\title{
Research on Young Pioneer Counselor's Sex Education Curriculum Leadership
}

\author{
Yunfeng Huang \\ College of Teachers \\ Chengdu University \\ Chengdu, P. R. China 610106
}

\begin{abstract}
Young pioneers counselors sex education curriculum leadership refers to young pioneers counselors' ability to lead and guide in the activities of sex education course design, development, implementation and evaluation, including Children's sex education curriculum value insight, Vision of foresight, resources integration ability, implementation guidance and evaluation force and so on. Young pioneers counsellors sex education curriculum leadership help children understand sex correctly, accept your body and sex, know the necessary knowledge of sexual protection, so as to promote the development of children's physical and mental health. Young pioneers counselors sex education curriculum leadership can be upgraded through some ways such as workplace learning, reflective practice, study community interaction and interregional communication.
\end{abstract}

Keywords-sex education; curriculum leadership; connotation function; improving path

\section{INTRODUCTION}

Sexual health education in China has been developing fast since the 1980s. There is encouraging progress in theoretical and practical aspects. However, the sexual health education for children has not received due development. There still exists a lot of misunderstanding and confusion of sexual health education for young children. Have young children started having sex? Do you need to have sexual health education in children? Should children's sexual health education be done? How do we do that? What do you do in the children sexual health problem, especially as a young pioneer instructor? These problems, such as the time and method of education of children's sexual health, are important questions to be discussed scientifically.

\section{ThE PRACTICAL SignifiCANCE OF YOUNG PIONEERS COUNSELORS SEX EDUCATION CURRICULUM LEADERSHIP}

\section{A. Realistic Demand: the Full Development of Children's Physical and Mental Health}

The phenomenon of young children stroking their genitals to get the pleasure of the activity occurs. The boy

This dissertation is the periodic research fruit of key project "young pioneers counsellors sex education curriculum leadership" (project number: 16 szsjyz-04) funded by Sichuan province philosophy social sciences key research base--children's organization and ideology education research center in Sichuan province. feels the penis, makes it erect and gets pleasure; it is not uncommon for a girl to touch the mound, or feel pleasure in the angle of the friction seat. According to Freud, babies are also libido. Their sexual development can be divided into three stages. It's the first stage of the baby's birth to the first year or so, also known as the lip stage. This stage is mainly manifested as the mouth sucking movement. The second stage is from about one year to three, four. It is mainly manifested as the pleasure of the anus, also known as the anal period. The performance of the anal stage is to love to procrastinate, play defecate and rub the anus. In the third stage, at the age of 3 to 7 , the boy is proud and proud of his penis. The girl envies the boy's penis, because he does not feel inferior and shy. Children in the worship of the penis have a sense of the difference between genitalia, and are also curious about the genitalia of adults and other children. So there will be sex games and behaviors of exploring sex between boys and girls. (1)

American psychologist Kohlberg also divided the development of children's sexual consciousness into three stages. He believed that the first stage was at the age of two to three, which was the age of basic gender identity. At this time, children can be aware of their gender. The second stage was at the age of three to five, which was the age of gender stability. At this time, children know that their gender will not change. The third stage was at the age of five to seven, which was gender indeterminate period. At this stage, children begin to explore the fundamental differences between genders. They knew that factors such as gender and appearance were irrelevant. Ji Jianrong (2) once did an investigation. He found that $90 \%$ children are curious and confused about the boy standing with urine and the girl squatting in the urine. In primary school the phenomenon that the boy calls girl wife and the girl calls boy husband is also common. This is the phenomenon of children's exploration of sex, which indicates that the development of sexual consciousness exists objectively.

Therefore, for the all-round development of children's physical and mental health, in this period, children's education is very necessary. According to the study on the development of children's consciousness, in this period sexual education is very important for children to understand their own gender and form the right gender role. Meanwhile, the sex education in the period is also necessary for children 
to understand one's own body parts scientifically, especially the sexual organs and their functions. Sex education in this period can also address children's puzzles and meet your child's curiosity. It is very beneficial for their physical and mental health.

Children's sex education is important, and the sooner they start, the better off they will grow. Children's education is also an important part in the development of a person's life. Jordan believes that two of the best times for sex education are 5 and early adolescence. (3) In China, we pay more attention to the education in adolescence, and parents and schools are conscious. However, there is a lack of attention to children's education, and some are not even aware of it. The theory and practice of children's education is still in its preliminary stage, and it is far from enough to meet the actual sexual health development needs of children.

\section{B. Requirements of The Times: the Ability of Young Pioneers to be Professional}

In 2012, the ministry of education issued the "primary school teacher professional standard (trial)". (4) (Hereinafter referred to as the standard). We hope to strengthen and enhance the professional competence of primary school teachers through standardized standards. "Standard" emphasizes that students should adhere to the basic principles of "students for base, ethics first, ability to focus, and lifelong learning". Primary school teachers understand the physical and mental development needs of children, and master the characteristics and laws of children's physical and mental development, including children's sexual psychology and sexual physiology, which are very important and necessary. Children's sexual development of physical, psychological, and even what is the development characteristic of sexual ethics, law of development, what are the strategies and methods can better promote the health development are also the important content of elementary school teachers' professional ability.

In the new historical period, in the face of the comprehensive development requirements of young children in the new era, primary teachers are required to have higher professional level. As an important team of primary school teachers, the guidance of young pioneers is also very important. Among them, the curriculum leadership of the instructor of the young pioneers is an important aspect of the professional competence of primary school teachers. To effectively develop children's sex education, the young pioneers counselors are required to insight into the important value and significance of children's sex education, to design, develop and implement children's education courses and be able to evaluate the effects of education. These are important aspects of the leadership of the children's education curriculum and an important aspect of the professional competence of young pioneers.

\section{Missing Appeal: the Current Lack of Children's Education}

In the present situation of our country as a whole, children's sex education is absent. Lack of knowledge about children's sexual development can lead to the lack of children's education. This is detrimental to the healthy development of children's sexual and sexual psychology. Some erroneous practice of teachers and parents, can also lead to the deformity of the sexual development of children, some will leave shadow, let the children form error sexual mores, think sex is dirty, guilt, shame, dirty things.

These issues highlight the absence of real neutral education. To solve this practical problem, it should be an effective way to improve the leadership of education.

\section{THE CONNOTATION OF THE LEADERSHIP OF EDUCATION CURRICULUM FOR YOUNG PIONEERS}

The sexual education leadership of the young pioneers is an important aspect of the professional competence of the counselors of the young pioneers, and an important part of the professional quality of the counselors of the young pioneers. The sexual education leadership of the young pioneers has an important role to play in promoting the healthy development and lively growth of young children.

\section{A. The Meaning of Young Pioneers Counselors Sex Education Curriculum Leadership}

The leadership of the young pioneers of education courses refers to the ability of young pioneers to design, develop, implement and evaluate children's education curriculum. This ability is based on the modern curriculum concept, which is to adapt to the children's physical and mental health development rules. This ability is also the requirement of the professional development of modern young pioneers, which is an important content of the professional quality of the counselors of young pioneers.

\section{B. Core Elements of the Leadership of the Young Pioneers Sex Education Curriculum}

The core elements of sex education curriculum leadership include children's sex education curriculum value perspective, children's sex education curriculum vision foresight, children's sex education curriculum resources integration, children's sex education curriculum implementation guidance force and children's sex education curriculum evaluation exciting force, etc. As shown in the "Fig. 1". 


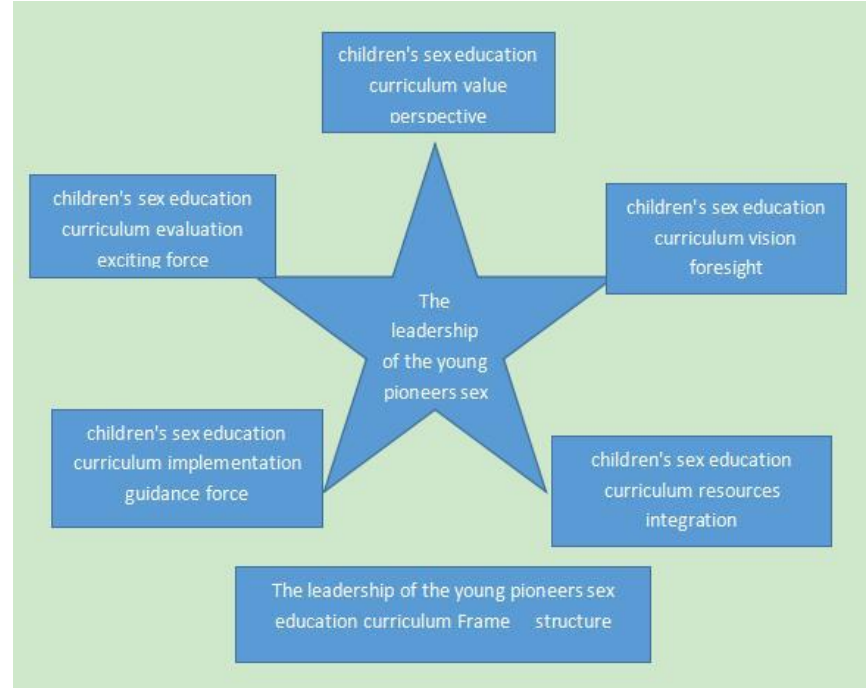

Fig. 1. The core elements of sex education curriculum leadership.

The core elements of curriculum leadership for children's teacher education are based on a few core questions to be answered based on children's education curriculum. These core questions are: why do children need to be taught education? What is its value? What kind of vision does the education program help children develop? What resources does the education curriculum need to integrate? How to integrate? How to conduct effective guidance in the implementation of education? After the implementation of education, how to evaluate?

The meaning of the core elements of the curriculum leadership of children's teacher sex education is explained as follows:

1) Children's sex education curriculum value perspective: The value insight of children's education courses refers to the ability of young pioneers to gain insight into the value and value of children's education curriculum. This is one of the core elements of the leadership of education curriculum for young pioneers. Only when young pioneer counselors can deep insight into the value of children's sex education classes, can they be active in children's sex education curriculum design, development, implementation and evaluation activities.

2) Children's sex education curriculum vision foresight: The vision of children's education curriculum vision is the ability of young pioneer counsellors to make a vision of children's physical and mental health after the implementation of education curriculum. Children's sex education classes need young pioneers counsellors to have certain ability foresee in the aspect of helping children improve sexual physiological knowledge and promote the formation of healthy sex psychology, etc. When our ability to foresee becomes stronger, we can have more clear sense to the healthy growth of children in the future. We can also have more dynamic and efficiency in our children's sex education curriculum design, development, implementation and evaluation, etc.
3) Children's sex education curriculum resources integration: The whole combination of education curriculum resources refers to the ability of young pioneer counsellors to integrate children sex education curriculum resources. How to integrate children's sex education curriculum resources according to children's physical and mental health law of development, and the psychological features of cognitive development so as to get better effect of sex education, depends largely on children's teacher education curriculum resources integration ability. Teachers with strong ability of children's sex education curriculum resources integration can not only properly design and develop more suitable sex education courses for children, but also teach students in accordance of their aptitude and obtain the ideal effect.

4) Children's sex education curriculum implementation guidance force: Children's sex education curriculum implementation guidance force means that the young pioneer counselors in the concrete implementation of the process of children's sex education classes, guide the children's understanding of the relevant knowledge of sexual physiology, form healthy sexual psychology in accordance with children's cognitive, and have certain perception of sexual ethics, etc. Children's sex education curriculum implementation guidance force emphasized teachers in curriculum implementation activities, to carry out on the children's guidance, give priority to children's own activities, and help children achieve the objectives of the sex education classes.

5) Children's sex education curriculum evaluation exciting force: Children's sex education curriculum evaluation exciting force, refers to the ability that the children's teachers evaluate children's sex education curriculum implementation after early childhood sexual education curriculum implementation, and through the evaluation, to achieve the incentive. Any complete education class activity needs to be evaluated after the completion of the activity, so as to summarize the previous activities and provide reference and reference for the subsequent activities. But such assessments should emphasize the need for incentives. This motivation is not only for children involved in the activity, but also for teachers and even parents who are indirectly involved.

\section{IMPROVInG PATH OF YOUNG PIONEERS COUNSELORS SEX EdUCATION CURRICULUM LEADERSHIP}

Curriculum leadership for young pioneer counsellors is of great significance to children's development. It is also an important part of the professional development of the counselors of young pioneers. From its path of ascension, it is possible to proceed from the following aspects:

\section{A. Workplace Learning}

Teacher's work field learning refers to a teacher's study in workplace for work and based on work. The nature and characteristics of teacher's work determine that the work 
field should be ideal to promote the professional growth of teachers. The learning strategy of the work field is selflearning, mentoring, secondment learning. [5]

The content of self-learning includes basic theories about curriculum affairs, especially the design, development, implementation and evaluation of children's education curriculum. Advisor guidance is a child sex education curriculum expert, and also a path to answer the question and solve the puzzle as to the young pioneer instructors' question and confusion in the sex education curriculum affairs. Secondment learning is a way for young pioneer counsellors to improve their own curriculum leadership by exchanging and learning from other schools.

Work field learning is one of the practical and effective ways to improve the leadership of education. In Sichuan province, there are many primary schools that have been taught sex education classes. To effectively implement these courses, young pioneer instructors will be required to have strong leadership of education. But when it comes to sex education, teachers tell a lot of difficulties and confusion.

In response to the confusion of teachers, the well-known professor of sex education and Professor $\mathrm{Hu}$ Zhen of Chengdu University gave guidance. She suggested that teachers study the sex education curriculum basic theory and basic knowledge in the work. According to the work situation, it is available to arrange the time practically. Know the basic common sense of education and the education method. For example, learn the international education guidelines, learn and learn about children's sexual psychology, sexual development laws and so on. Professor $\mathrm{Hu}$ also discusses some typical problems with others. Under the guidance of expert advisors, teachers combine work practice to carry out the work field learning of children's education curriculum, thus the leadership of education curriculum is gradually cultivated and promoted.

\section{B. Reflective Practice}

Reflective practice refers to the reflection of teachers after practice, and through the use of the tacit knowledge cultivated by experience, the question is repeatedly constructed and thought, in order to obtain the effective solution of the problem. The effective strategies of reflective practice are dialogue with oneself and communication with peers. It can effectively promote teachers' professional development and improve teachers' curriculum leadership in communication with oneself and peer communication. [6]

Young pioneers counsellors in primary schools carrying out sex education attach importance to "reflective practice". They carry out the research according to the idea of "practice — theory - practice — reflection — practice — the promotion of results". As to "reflection", they emphasized that "the existing research achievements of the subject are summarized, analyzed and refined, forming certain teaching cases, case sets, empirical articles, research papers, etc. The existing education method and education strategy are reviewed, and the deficiencies are found and adjusted, improved and improved in a timely manner. Such research methods and practices have effectively promoted the teachers' sexual education curriculum leadership.

\section{Study Community Interaction}

The study of community interaction means that teachers form professional development community in different forms and form a form of ability promotion through mutual communication and communication. School preparation, teaching and research groups, mentoring pairs, class teachers and voluntary organizations are effective forms and practical paths for teachers to study the community. [7]

In the primary school of education, a research group has been formed to become a research community of education curriculum leadership development. We often discuss the sexual education problems that some small students will encounter. "Why did mom and dad get married?" "Why do mom and dad sleep together?" And the reason why a girl can't turn her skirt around and that the boy doesn't show small penis to others. As to these questions children often ask about the sex education, how to answer the children's questions will have a better effect? Everyone has a point of view. Through adequate communication, sometimes even heated debates, a more consistent "reference answer" is formed. This will greatly improve the quality of children's education curriculum and the leadership of education curriculum for young pioneer instructors.

\section{Inter-regional Communication}

Interregional communication refers to communication through interdisciplinary, cross-study period, interschool, inter-regional (district, county, city, province, and state). Through the breaking of the inherent discipline boundary, the boundary of learning period, the boundary of the school, and the boundary of the region, the communication can be carried out widely, which can inspire each other to enhance the leadership of teacher's curriculum. [8]

Interregional communication can easily bring new impact and thinking to teachers. Because of different subject areas, different characteristics of students, different geographical conditions can vary widely. These differences are more likely to arouse the interest and curiosity of teachers, thus obtaining new findings and promotion.

For example, in April 2016, the third sex education academic seminar was held in Sichuan province. From the whole province and even the whole nation, some young pioneer counsellors have exchanged views on children's sex education. In May 2017, UNESCO China representative office and Chengdu University jointly held the national education seminar for 2017. Many young pioneer instructors of primary school also attended the meeting and communicated about children sex education experience in the conference. They also listened to the sexual education experience of other young pioneer instructors.

He has a stone, can attack jade. Some primary schools have some mature experience, and some young pioneer counselors have made beneficial exploration. These can be used as reference and reference. In this way, you can reduce 
your time and energy for self-exploration, thus improving the leadership of the sexual education curriculum for young pioneer counsellors.

\section{CONCLUSION}

Although children are young, sexual physiology and sexual psychology have begun to develop. As counselors of young pioneers, we should carry out the effective education, so as to better promote the comprehensive and healthy development of children.

The physical and mental development of children, especially the physical needs of sexual development, and the lack of children's sex education, are the important problems that we should pay attention to in the work of education. For the development of child sex roles, Feng Ming believed the sooner sex education begins, the better the effect will be. [9]

\section{REFERENCES}

[1] Liu fang. Facing the problem of education in childhood, caring for the sexual health development of young children [J]. Time Education, 2009,(3).

[2] Ji Jianrong. Investigation and analysis on the current status of preschool children's education in China [J].educational innovation, 2008, (3).

[3] Jordan T.R.Rural parents' communication with their teenagers about sexual issues[J].Journal of School Health,2003, (8):338-344.

[4] http://old.moe.gov.cn//publicfiles/business/htmlfiles/moe/s6127/2011 12/127838.html.

[5] Huang Yunfeng. The exploration of the practice path of teacher curriculum leadership in the field of professional development [D].Chongqing: Doctoral dissertation of southwest university, 2015.

[6] Feng Ming. The present situation and methods of preschool children education $[\mathrm{J}]$ Journal of education college in Chongqing, 2012, (3):115-117. 